\title{
Fracture Phenomena in Amorphous Selenium
}

\author{
Lindegaard-Andersen, Asger; Dahle, Birgit
}

Published in:

Journal of Applied Physics

Link to article, DOI:

10.1063/1.1707823

Publication date:

1966

Document Version

Publisher's PDF, also known as Version of record

Link back to DTU Orbit

Citation (APA):

Lindegaard-Andersen, A., \& Dahle, B. (1966). Fracture Phenomena in Amorphous Selenium. Journal of Applied Physics, 37(1), 262-266. https://doi.org/10.1063/1.1707823

\section{General rights}

Copyright and moral rights for the publications made accessible in the public portal are retained by the authors and/or other copyright owners and it is a condition of accessing publications that users recognise and abide by the legal requirements associated with these rights.

- Users may download and print one copy of any publication from the public portal for the purpose of private study or research.

- You may not further distribute the material or use it for any profit-making activity or commercial gain

- You may freely distribute the URL identifying the publication in the public portal

If you believe that this document breaches copyright please contact us providing details, and we will remove access to the work immediately and investigate your claim 
tween each layer did not show this "antitraining" effect. Also copperplated $\mathrm{Nb}-25 \% \mathrm{Zr}$ wire showed the effect when wound in close-packed form, but did not show "antitraining" when 1-mil Mylar was placed between layers. We believe lack of proper cancellation of selffield can explain why other workers have not reported these effects. LeBlanc ${ }^{5}$ used only a single-layer noninductive coil and, furthermore, reported critical current vs field to only $10 \mathrm{kG}$. Yasukochi et al. ${ }^{18}$ used a two-layer noninductive coil in their work; however, a Manganin wire heater wound between the layers reduced the pack-

${ }^{18} \mathrm{~K}$. Yasukōchi, T. Ogasawara, N. Usui, and S. Ushio, J. Phys. Soc. (Japan) 19, 1649 (1964); 19, 137 (1964). ing factor. Fietz et al. ${ }^{19}$ did investigate multilayer noninductive coils, but Mylar sheets were inserted between layers.

\section{ACKNOWLEDGMENTS}

The author is grateful to Professor B. S. Chandrasekhar of Western Reserve University for many helpful experimental suggestions and valuable discussions of the interpretations and to G. J. Faychak for technical assistance.

${ }^{19}$ W. A. Fietz, M. R. Beasley, J. Silcox, and W. W. Webb, Phys. Rev. 136, A335 (1964).

\title{
Fracture Phenomena in Amorphous Selenium
}

\author{
A. LINDEgaARD ANDERSEN* \\ Technical University of Denmark, Physics Department III, Lyngby, Denmark \\ AND \\ BIRGIT DaHIE \\ Allmänna Svenska Elektriska Aktiebolaget (ASEA), Västeras, Sweden
}

(Received 16 April 1965)

\begin{abstract}
Fracture surfaces of amorphous selenium broken in flexure at room temperature have been studied. The fracture velocity was found to vary in different regions of the fracture surface. Peculiar features were observed in a transition zone between fast and slower fracture. In this zone cleavage steps with a nearly constant spacing of approximately $1 \mu$ were found. Occasionally long cleavage whiskers-up to some millimeters long-were observed. Within certain regions the cleavage steps were crossed and interrupted by two line systems. The maximum fracture velocity has been measured to $350 \mathrm{~m} / \mathrm{sec}$. Further the velocities of ultrasonic longitudinal and shear waves were measured to $1820 \mathrm{~m} / \mathrm{sec}$ and $930 \mathrm{~m} / \mathrm{sec}$, respectively. Based on these results the two line systems in the transition zone can be interpreted as "Wallner lines" with sources within the zone.
\end{abstract}

\section{INTRODUCTION}

$\mathbf{I}^{\mathrm{r}}$ $\mathrm{N}$ connection with an investigation of crystallization processes in selenium the authors have studied fracture surfaces of amorphous selenium. Due to its chain structure amorphous selenium can be regarded as a polymer. Hence such an investigation should be of interest in view of the widely studied fracture phenomena in high polymers.

In this paper some aspects of the fracture morphology of amorphous selenium are described, revealing that internal flaws are operative to produce Wallner phenomena.

\section{EXPERIMENTAL}

Plates, 2-4 mm thick, and rods with circular cross section, were cast from vacuum-distilled selenium. The specimens were broken in flexure at room temperature (approx $22^{\circ} \mathrm{C}$ ). At this temperature amorphous selenium

\footnotetext{
* Formerly at ASEA, Västerås, Sweden.
}

is a brittle material. Most of the specimens were broken manually without special arrangements. Some plates, however, were notched at an edge and broken by fourpoint bending.

The fracture surfaces were studied by dark-field illumination in a light microscope. Some surfaces were examined in an electron microscope by a two-step replica method (zapon lacquer and aluminum shadowed with $\mathrm{Pt}-\mathrm{Pd}$ ).

The fracture velocity in a notched rectangular plate $(180 \times 60 \times 2 \mathrm{~mm})$ broken by four-point loading was measured by a method decribed by Lundborg and Johansson. ${ }^{1}$ On the "tension surface" of the plate an aluminum layer is by masking technique vacuum-deposited in isolated strips perpendicular to the expected fracture direction. These strips are connected through resistors to a voltage source and a cathode-ray oscillograph in such a way that a voltage jump occurs when the crack passes the boundary between two aluminum strips.

${ }^{1}$ N. Lundborg and C. H. Johansson, Arkiv Fysik 4, 555 (1952). 
The velocities of ultrasonic longitudinal and shear waves were measured by a pulse method in a $10-\mathrm{mm}-$ thick selenium plate. The frequency of the ultrasonic waves was $4 \mathrm{Mc} / \mathrm{sec}$.

\section{RESULTS}

A typical fracture surface of a manually broken, unnotched plate can roughly be divided into five characteristic zones A, B, C, D, E as sketched in Fig. 1(a). The fracture surfaces of manually broken rods vary much more from case to case, but often the same zones appear as indicated in Fig. 1(b).

Zone $\mathrm{A}$, the initiation zone, is often a mirrorlike region with a circular boundary.

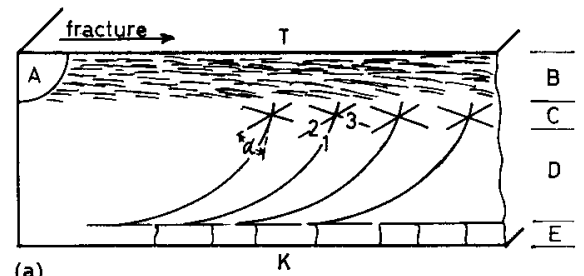

(a)

(b)

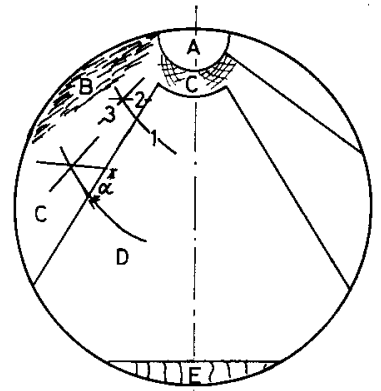

FIG. 1. Sketch of fracture surface. (a) Plate: $T$ tension surface; $\mathrm{K}$ compression surface; $\mathrm{A}$ initial zone; $\mathrm{B}$ rough zone; $\mathrm{C}$ zone with two line systems ( 1 and 2), striations and cleavage whiskers (3); D smooth zone with one line system (1); E curved zone with large cleavage steps approx perpendicular to the compression surface. (b) Rod: symmetrical fracture. The distribution of the characteristic zones and fracture markings described under (a) is indicated.

\%one $\mathrm{B}$ appears grey and dull in contrast to the rest of the fracture surface, which looks black and shiny. Under the light microscope zone B appears rough with a great number of "hackles," commonly with directional character. In plates, zone B has a width about onequarter of the plate thickness and extends to the tension surface. The degree of roughness is increasing toward the tension surface.

Zone $\mathrm{C}$, which is a transition zone between the rough zone $\mathrm{B}$ and the smooth zone $\mathrm{D}$, often displays the most interesting features as indicated in Fig. 1 and shown in the micrograph (Fig. 2) of a broken selenium rod. The main feature is striations (vertical in Fig. 2) which within certain regions are crossed and interrupted by two line systems. The striations which have an almost
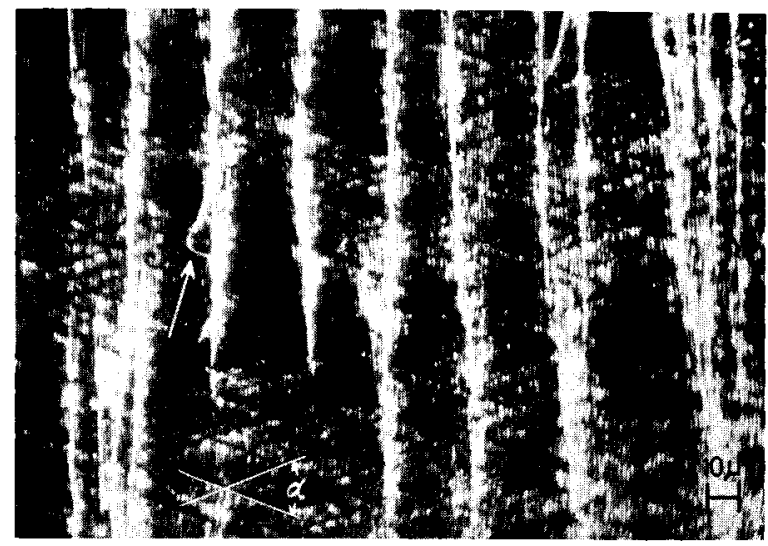

FIG. 2. Micrograph of zone C.

constant spacing of about $1 \mu$, presumably represent cleavage steps. The groups of bright, almost uninterrupted striations represent cleavage steps by which "cleavage whiskers" are formed. Such whiskers have been found in a wide variety of materials as described by Venables. ${ }^{2}$ The arrow in Fig. 2 indicates a whisker, which has been partly torn out from the cleavage step. Occasionally, large groups of whiskers forming steps occur as shown in the Fig. 3 micrograph, in which several partly loose whiskers can be seen. The cleavage whiskers are preferentially formed in curved or inclined regions of zone C. In thick specimens they can be several $\mathrm{mm}$ with the "diameter" rarely exceeding $1 \mu$. By replicating for observation in the electron microscope, the whiskers often are stripped off and transferred to the replica, as

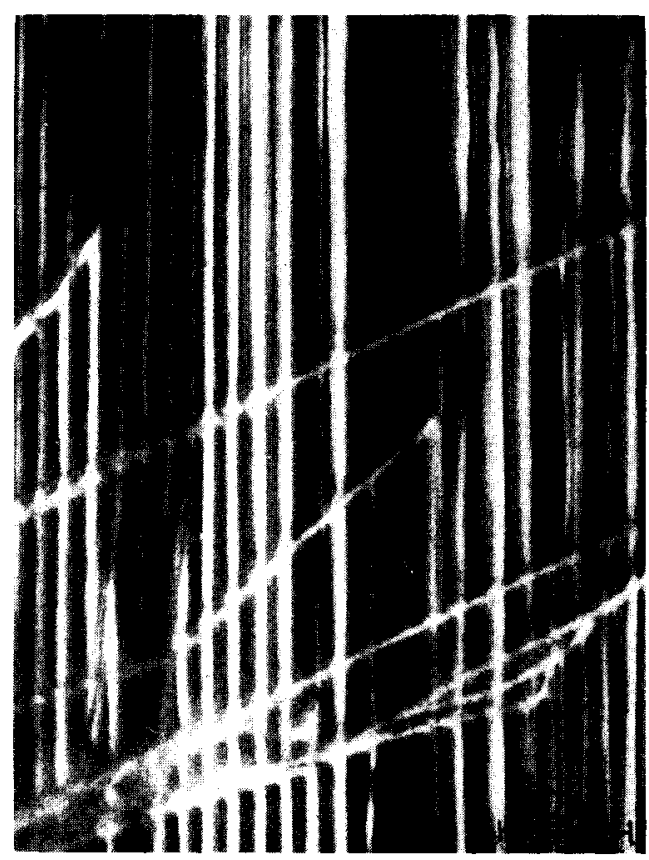

FIg. 3. Micrograph of cleavage whiskers in zone C.

${ }^{2}$ J. D. Venables, J. Appl. Phys. 31, 1503 (1960). 


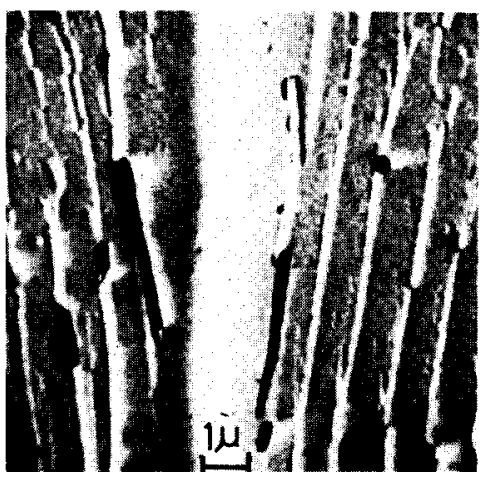

FIG. 4. Electron micrograph of cleavage steps showing parts of some stripped-off cleavage whiskers.

shown in the electron micrograph in Fig. 4. Whiskers stripped off by adhesive tape were investigated by $x$-ray diffraction. Any crystallinity or orientation could not be detected. In a fractured selenium crystal cleavage whiskers are easily formed, and they are clearly crystalline in contrast to the whiskers from amorphous selenium.

The angle $\alpha$ between the two line systems 1 and 2 in Fig. 1 (also indicated in Fig. 2) has been measured on micrographs of several fracture surfaces. This angle was found to be nearly constant, $43^{\circ} \pm 2^{\circ}$. The supplemental angle of $\alpha$ is bisected by cleavage striations. Based on these observations, it is made evident in the next section that the lines are attributable to the interaction of the fracture front with stress waves. They are so-called "Wallner lines," discovered by Wallner in fractured glass rods and studied in detail by Smekal. ${ }^{4}$

The microstructure of interrupted cleavage steps was studied in detail. When two systems of Wallner lines cross a system of cleavage steps these are broken up into dotted lines, the dots occasionally forming a highly symmetrical pattern, as shown in the Fig. 5 micrograph. A typical appearance of the microstructure as displayed by the electron microscope is shown in Fig. 6. Some minute cleavage whiskers are observed. The applied direction of shadowing reveals only one system of Wallner lines, the spacing of which is seen to be almost constant and somewhat smaller than the spacing of

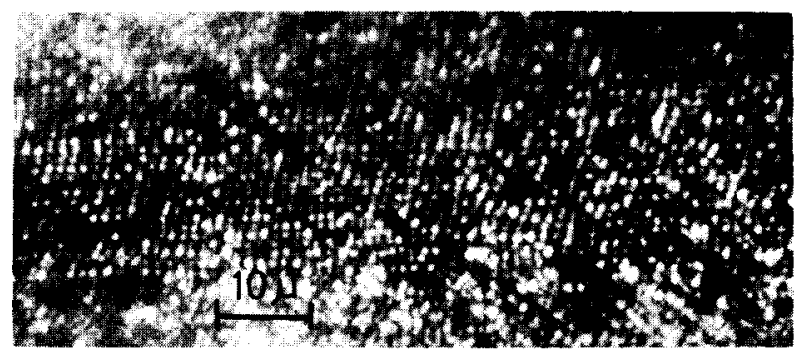

FIG. 5. Micrograph of symmetrical dot pattern caused by two systems of Wallner lines crossing a system of cleavage steps.

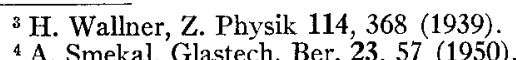

cleavage steps. Between the main cleavage steps some very short ones situated along the Wallner lines are observed.

Zone D, Fig. 1, is commonly a smooth region with only one system of Wallner lines in fractured plates, as shown in the Fig. 7 micrograph. The Wallner lines display a "granulated" structure. Occasionally, large cleavage steps emerge in zone $D$, as shown in the micrograph in Fig. 8. When this is the case, more than one line system often appears, as seen in Fig. 8.

Zone $\mathbf{E}$ is commonly curved. In fractured plates large cleavage steps approximately perpendicular to the compression surface are observed.

The results described above refer to manually broken specimens. When selenium plates are notched and broken by four-point loading the same general picture of the fracture surface is obtained, except that the surface is more flat and the formation of cleavage whiskers and Wallner lines is less pronounced.

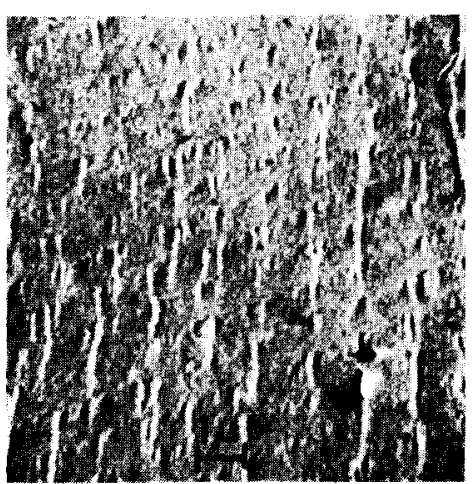

FIG. 6. Electron micrograph of cleavage steps showing interruptions by one system of Wallner lines.

The results obtained by the velocity measurements are: fracture velocity $v_{f}=350 \mathrm{~m} / \mathrm{sec}$; velocity of ultrasonic longitudinal waves $v_{1}=1820 \mathrm{~m} / \mathrm{sec}$; velocity of ultrasonic shear waves $v_{s}=930 \mathrm{~m} / \mathrm{sec}$. Young's modulus $E$ and Poisson's ratio $\mu$ can be calculated from the values of $v_{1}$ and $v_{s}$ and the density of amorphous selenium $\rho=4.26 \mathrm{~g} / \mathrm{cm}^{3}: E=9.8 \times 10^{10} \mathrm{dyn} / \mathrm{cm}^{2}$ and $\mu=0.32$. The measurements were performed at room temperature $\left(22^{\circ} \mathrm{C}\right)$.

\section{DISCUSSION AND INTERPRETATIONS}

The results are most clearly interpreted for fractured plates and the present discussion is therefore restricted to this kind of specimen.

\subsection{Course of Fracture}

In a brittle material the main cleavage steps always run approximately perpendicular to a moving fracture front. Hence the geometrical course of fracture can be deduced if cleavage steps occur over the whole fracture 
surface. This occasionally was the case, as partly shown in Fig. 8.

Based upon observations of cleavage steps, a sketch indicating successive positions of the fracture front was drawn as shown in Fig. 9. If the positions are drawn for equal time intervals, the fracture or crack velocity is proportional to the perpendicular distance between successive front positions. The measured crack velocity at the tension surface was found to be constant over the measured distance (which did not include the initial zone). The fracture fronts, which in Fig. 9 are drawn with equal spacings at the tension surface, therefore correspond to equal time intervals. It can be seen that the crack velocity is fairly constant in zones B and C, but is decreasing in zone $\mathrm{D}$ toward the compression surface. The transition from maximum crack velocity to

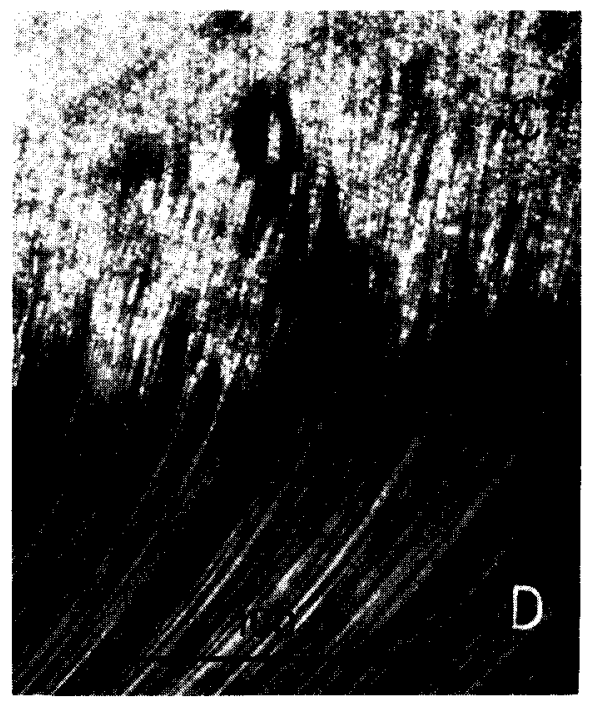

FIG. 7. Micrograph of Wallner lines emerging from zone $\mathrm{C}$ into zone $\mathrm{D}$.

the slower one is not quite continuous as indicated by the small breaks in cleavage steps shown by arrows in Fig. 8. At the boundary between zones $\mathrm{D}$ and $\mathrm{E}$ the crack velocity is almost zero, the cracks lining up side by side until a fracture front parallel to the compression surface is formed. This front then moves approximately perpendicular to the compression surface and finishes the fracture.

\subsection{Fracture Markings}

The roughness in zone B (Figs. 1 and 8) is caused by secondary fractures, i.e., microfractures, which the stress field, surrounding the main fracture, induces ahead of the front at microscopic inhomogeneities. The tension stress in front of the main fracture is maximum at the tension surface. Hence that region is most severely subjected to secondary fracture and the degree of roughness should therefore be increasing toward the tension surface, which is in fact observed.

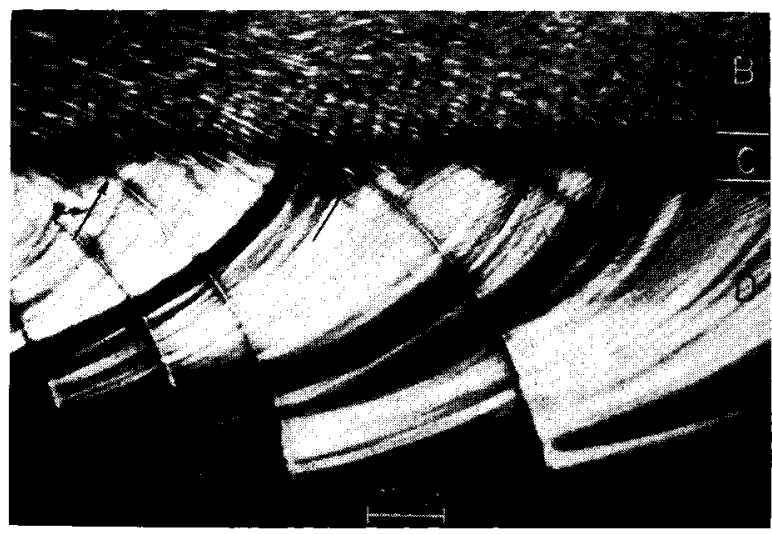

FIG. 8. Micrograph of zones B, C, and D showing large cleavage steps in zone $\mathrm{D}$.

The regularly spaced cleavage steps in zone C (Figs. 2 and 3 ) imply that the profile of the fracture surface is regularly undulated. The projection of the moving fracture front on a plane perpendicular to the fracture surface has the form of a stationary wavelike curve. A similar phenomenon has been observed by Berry ${ }^{5}$ in polymethylmethacrylate, the spacing in this material being 100 to 1000 times larger than in amorphous selenium.

Kies, Sullivan, and $\operatorname{Irvin}^{6}$ have concluded that cleavage steps extending in the direction of fracture are associated with secondary fractures. Unfortunately the present investigation does not reveal the nature of the imperfections at which the secondary fractures are initiated. Further, it is difficult to explain the regularity of the spacing of the cleavage steps as it is not very probable that the imperfections should be equally spaced in the unbroken material.

The two systems of dark lines in zone C (Fig. 2) can be interpreted as Wallner lines if one assumes that the sources of the lines, i.e., the flaws, from which stress waves are released, are localized in this zone. The moving fracture front can be regarded as straight in the rather narrow zone $\mathrm{C}$, except for the undulations perpendicular to the fracture surface, and the fracture velocity is close to the measured maximum value $v_{f}$.

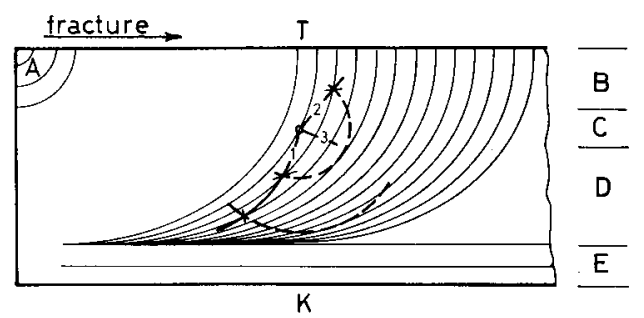

FIG. 9. The course of fracture indicated by successive positions of the fracture front. The letters and numbers have the same meaning as in Fig. 1.

${ }^{5}$ J. B. Berry, J. Appl. Phys. 33, 1741 (1962).

${ }^{6}$ J. A. Kies, A. M. Sullivan, and G. R. Irvin, J. Appl. Phys. $21,716(1950)$. 


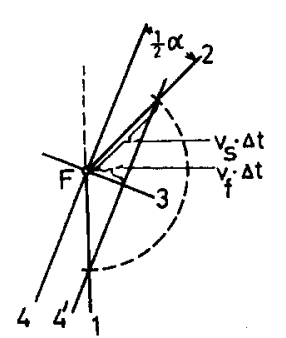

FIG. 10. Formation of a pair of Wallner lines, 1 and 2 , when the fracture front, 4 , passes a flaw $F$. The dotted circle indicates the position of the released shear wave when the fracture front is in position $4^{\prime}$. The direction of cleavage steps is indicated by line 3 .

When the fracture front passes a flaw, by which stress waves are released, a pair of Wallner lines are formed as shown in Fig. 9. The released stress wave is shown in two successive positions (indicated by dotted circles) with the same time intervals as the fracture fronts. The intersections with the fracture front forming points of the Wallner lines are indicated by crosses. Smekal ${ }^{4}$ has shown that the formation of Wallner lines is due to the shear part of the released stress wave. The angle $\alpha$ between the two lines is then determined by (Fig. 10):

$$
\sin \left(\frac{1}{2} \alpha\right)=v_{f} / v_{s}
$$

Using the measured values of $v_{f}$ and $v_{s}$, we find $\alpha=44.2^{\circ}$, which is in good agreement with the observed value $43^{\circ} \pm 2^{\circ}$.

Presumably the sources of the Wallner lines are minute secondary fractures, released at imperfections in the material. The Wallner lines of ten have an almost constant spacing as observed in the electron microscope. Such lines evidently have their origin at equally spaced sources. This suggests that these sources are formed by a sort of self-reproducing mechanism, similar to one observed by Smekal ${ }^{4}$ in a broken thick-walled glass capillary, where he observed a great number of successive equally spaced pairs of Wallner lines behind the capillary hole. The short cleavage steps between the main steps in Fig. 6 also suggest that a self-reproducing mechanism is operative. The short steps between two main steps in many cases are very alike and have almost constant spacing. The formation of the short steps can be explained in the following way. When the stress wave meets one of the main cleavage steps the wave is heavily modulated and the modulation is revealed by the moving fracture front as short cleavage steps. The similar regularity of the spacing of Wallner lines and main cleavage steps suggests that the origins of Wallner lines are closely connected with the secondary fractures causing the cleavage steps.

The assumption that the sources of the Wallner lines are concentrated to zone $\mathrm{C}$ is consistent with the course of the one line system commonly observed in zone D (Fig. 7 and Fig. 9). The granulated appearance of these lines implies that the fracture front also in this zone is to a certain degree undulated. When in addition to the usually observed line system other line systems occur in zone D (Fig. 8), these have their origin at large cleavage steps within this zone.

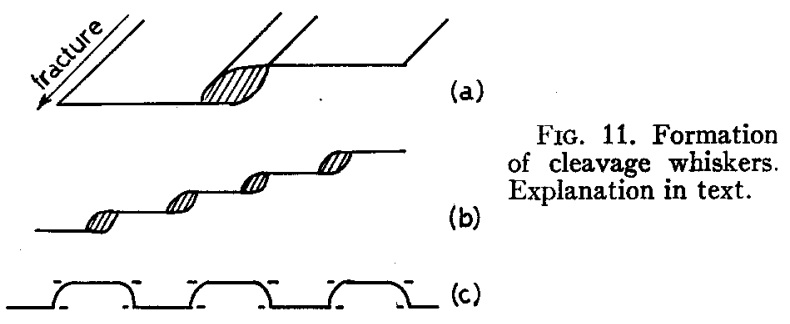

4.3. Cleavage Whiskers

The formation of cleavage whiskers has been considered by Venables. ${ }^{2}$ The mechanism proposed is that the two fracture planes at a cleavage step are joined by two "cracks" between which a whisker is formed during the fracture course [Fig. 11(a)]. The observed whiskers were preferentially formed where the average fracture surface was inclined or curved. In that case the profile of the fracture surface probably is as shown in Fig. 11(b), where sections of whiskers are also indicated. When the average fracture surface is flat the profile is probably as shown in Fig. 11(c). The fracture surface can be regularly biplanar, but the formation of whiskers is restricted due to mutually cancelling stresses of the cleavage steps. The stresses at cleavage steps have been considered by Orowan. ${ }^{7}$

\section{CONCLUSION}

In amorphous selenium plates broken in flexure at room temperature the fracture velocity varies from a maximum value at the tension surface to small values toward the compression surface. The fracture surface displays some peculiar features in the transition zone between fast and slower fracture. These features are cleavage steps and cleavage whiskers with a nearly constant spacing of approximately $1 \mu$, and two line systems which cross and interrupt the cleavage steps. An explanation of the conditions of the formation of cleavage whiskers can probably be based on the stress distribution at cleavage steps. The two line systems have been interpreted as Wallner lines with sources situated in the transition zone. However, a more detailed study is necessary in order to reveal the nature and the formation of these sources, which possibly are also responsible for the formation of the cleavage steps.

\section{ACKNOWLEDGMENTS}

We are indebted to the directory of ASEA, Sweden for permission to publish this work, which started as a byproduct of an investigation of crystallization processes in selenium during one of the authors' (ALA) employment at ASEA. He is indebted to Professor N. I. Meyer at the Technical University of Denmark for giving him opportunity to finish this work. He also gratefully acknowledges the help of S. A. Lund (Danish Welding Institute), who assisted in the ultrasonic measurements.

\footnotetext{
${ }^{7}$ E. Orowan, Dislocations in Metals (AIME, New York, 1954), p. 144 .
} 